\title{
Identification of Industrial Land Parcels and Its Implications for Environmental Risk Management in the Beijing-Tianjin-Hebei Urban Agglomeration
}

\author{
Zishu Wang ${ }^{1,2}$, Jie Zhao ${ }^{2}$, Sijie Lin ${ }^{1,3}$ and Yi Liu ${ }^{1, *}$ \\ 1 School of Environment, Tsinghua University, Beijing 100084, China; wzs@bjenv.com (Z.W.); \\ linsj@sustc.edu.cn (S.L.) \\ 2 Department of Ecology and Environment Research, Beijing Tsinghua Holdings Human Settlements \\ Environment Institute, Beijing 100083, China; zj@m.bjenv.com \\ 3 Beijing Huanding Environmental Big Data Institute, Beijing 100083, China \\ * Correspondence: yi.liu@tsinghua.edu.cn; Tel.: +86-10-62796052
}

Received: 3 December 2019; Accepted: 23 December 2019; Published: 24 December 2019

\begin{abstract}
Due to rapid, sprawling urban and industrial development, urbanization in China has led to serious environmental pollution with subsequent risks to human well-being. Landscapes comprised of intermingled residential and industrial areas are common across China, which is a large challenge for effective urban planning and environmental protection. Being able to identify industrial land across the urban landscape is critical for understanding patterns of urban design and subsequent consequences for the environment. Here, we describe a method to quickly identify industrial parcels using points of interest (POIs) and large-scale spatial data. We used the Beijing-Tianjin-Hebei urban agglomeration as a case study and identified 8325 square kilometers of industrial land, accounting for $30.7 \%$ of the total built land. Based on ground-truth randomly-sampled sites, the accuracy, precision, and recall of identified industrial areas were $87.1 \%, 66.4 \%$, and $68.1 \%$, respectively. Furthermore, we found that over $350 \mathrm{~km}^{2}$ of the industrial parcels were high human settlement risks and mainly were distributed in Tianjin and Tangshan city. Over $28.8 \%$ of the identified industrial land parcels might be at the risk of potential soil contamination. The results can be helpful in future urban planning and for identifying urban areas that are targets for implementing environmental risk management and remediation.
\end{abstract}

Keywords: industrial land identification; POIs; large-scale spatial data; environmental risk management; Beijing-Tianjin-Hebei urban agglomeration

\section{Introduction}

Rapid urbanization and global industrialization in recent decades have led to extensive sprawl of developed land and environmental risks to people living in urban residential landscapes [1,2]. From 1978 to 2017, Chinese urban dwellers have increased from $17.9 \%$ to $58.5 \%$ [3]. Chinese urbanization is always accompanied with high energy consumption and extensive land utilization [4,5]. While urbanization have improved economic development and the quality of life in China, it has also caused substantial environmental degradation [6], especially in the form of air pollution, urban heat islands, greenhouse gas emissions, and extensive landscape development for cities and industries [7,8].

In 2014, the "National New-Type Urbanization Plan (2014-2020)" was released by the Chinese government to promote a new path toward sustainable urbanization [9]. One of the central aspects is optimizing the spatial layout of urban landscapes and improving quality of life for urban residents. Distinguishing the area and spatial distribution of industrial land parcels is key to optimizing intensive 
and efficient urban planning that includes creating healthy, natural, and human environments. However, there are currently few data in China recording which partials contain industrial land use and what their spatial distribution is in China. To date, little progress has been made in developing methods to identify industrial land or associated environmental impacts.

Current methods for identifying land use classifications rely on remote sensing technology $[10,11]$ and the land use categories are commonly divided into settlements, vegetation, barren land, water, and farmland [12,13]. However, existing remote sensing data and algorithms cannot obtain differentiate industrial land parcels for its non-objectivity and low quality [14]. The development of Internet information technology has produced more reliable data resources, such as points of interest (POIs) and OpenStreetMap (OSM), and brought out the relevant methods of land use identifications using the big data $[15,16]$. In this study, we propose a method to quickly identify industrial land based using large scale spatial data, including points of interest (POIs), OpenStreetMap, land use and remote sensing data, and parcel-scale population density information. Using the method, we identified industrial parcels in the Beijing-Tianjin-Hebei urban agglomeration and we discuss the uncertainty and possible applications for urban environmental risk management.

\section{Orientation on Industrial Land Parcels and Environmental Risks}

Built-up land comprised of intermingled residential and industrial parcels is common in China, and this form of mixed land use is a grand challenge for urban planning and environmental protection [17]. Megacities and surrounding regions are the hot zones for urbanization and industrialization, which always accompany severe environmental problems [18,19]. Zhang et al. found that Beijing-Tianjin-Tangshan region experienced rapid urbanization from 1970 to 2013, and the newly developed land was converted from cultivated land and other built-up land [20]. Existing studies in China show that urbanization and industrial development were the two main factors affecting health risks of fine particle $\left(\mathrm{PM}_{2.5}\right)$ [21,22]. Meanwhile, the functions and environmental impacts differ greatly in various built-up land parcels [23]. Industrial land parcels are one of the most essential components, with the proportion from $15 \%$ to $30 \%$ in urban planning due to national regulations. During the past decades, the government was more likely to provide industrial land for attracting investment in China [24], and thus industrial parcels might sprawl quickly. Jiang et al. found that the industrial and residential parcels in Beijing presented a disordered urban spatial structure during the urban sprawl process from 2001 to 2012, because of the different sprawl patterns [25] (Figure 1b). Sun et al. found that the new industrial land was intensively distributed in the north and the southeast of Beijing, and pointed out that the increase of the industrial land was negatively related to population density [26]. Otherwise, industrial parcels with polluting factories are regarded as major sources of environmental risks in urban areas [27]. Industrial parcels with polluting emissions (e.g., power plant and steel factory) are found to be obvious contributions to soil contamination and the effects decreased from the emission source to the surrounding environment [28]. The Chinese government complimented soil contamination monitoring and a remediation plan to control and reduce the environmental risks in 2016 [29]. One of the basic tasks is to screen and confirm the potential contaminated land parcels, mostly caused by industrial pollution [30]. Hence, industrial parcels become important restructuring, optimizing, and monitoring objectives for urban land use and environmental risk management.

In addition, the industrial parcels and their distribution can bring out other human settlement risks for the surrounding environment and difficulties for urban land use planning. After rapid urban development and construction, many industrial parcels that used to be far away from the city are nearby or surrounded by residential and commercial parcels (Figure 1). The study of urban built-up land sprawl in Beijing found that the structure of the built-up land changed from single residential structure to industrial-residential structure [17]. The mixed distribution of industrial and residential parcels could produce potential environmental and health risks to the citizens [31]. The polluting industrial parcels might increase the exposure risk of air pollution, and cause soil contamination to nearby residents [21,28]. Ensuring the safety of human settlements has been an essential issue for 
urban sustainability in China. Therefore, the government and urban planners begin to realize the potential environmental risks for the mixed structure of urban land use, and to promote restructuring and optimization for industrial parcels. One of the policies is the relocation and reuse of industrial land parcels under progress, especially in some of the megacities (e.g., Beijing). Industrial shutdown or relocation is treated as a crucial way to reduce environmental pressure and risks [32]. The government proposed a decentralization strategy to transfer the low-end, heavy pollution industries from Beijing to surrounding cities in 2015 [33]. However, after the relocations, the former industrial parcels in the urban areas still might have potential environmental risk for a long time. The new "Beijing Urban Master Plan (2016-2030)" has taken human settlement quality and risk control as an essential goal. Under the background of new urban planning and land use policy in Beijing, the reuse of industrial parcels is a crucial path for the city's regeneration and future development. Reasonable monitoring and remediation of industrial land parcels are fundamental before the reuse. However, it is difficult to identify the potential objects and to promote urban environmental risk management, because of the mixed land use and disordered spatial structure. Traditional methods mainly rely on manual investigations and evaluations, which need a lot of time and manpower. This restriction therefore becomes a crucial issue for promoting urban land use planning and environmental risk management.

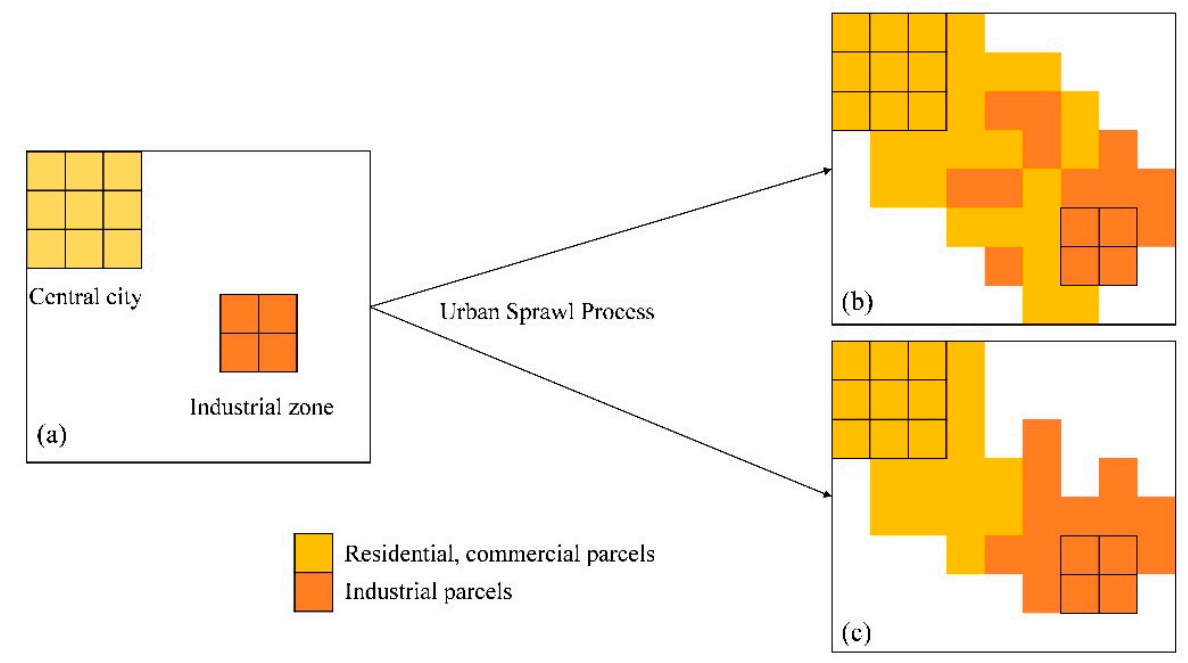

Figure 1. The analytical graph of the urban sprawl process in China. (a) The urban spatial pattern before rapid urbanization; (b) industrial parcels surrounded by residential parcels after urban sprawl; (c) industrial parcels nearby to residential parcels after urban sprawl.

Fast and accurate identification of industrial parcels might play a primary role in understanding the internal structure of urban land use and implications for environmental risk management. As we all know, how to classify land use and land cover (LULC) is an important topic for urban planning and land use policy research. Current studies mainly use remote sensing data and geographic information system (GIS) technology to identify the main categories (e.g., built-up land, forest land, etc.) to analyze the land use and cover changes [34]. Because of the similarity of spectral characteristics, the methods using remote sensing data cannot quickly and accurately classify the mixed land use pattern, especially the industrial land parcels [15,17]. Using multi-source big data and new technology, researchers have explored new methods to identify more details of built-up land [23,35]. Jia et al. advanced a method of mapping the urban land use with more detailed classifications and higher accuracy using remote sensing imagery and mobile phone positioning data [36]. Zhang et al. used integrated data of Google Street View (GSV) and other high resolution orthoimagery to develop the method of parcel-based urban land use classification (e.g., single-family house, commercial, and industrial building) [23]. Liu and Long proposed a method to automatically identify built-up land parcels using OpenStreetMap (OSM) and points of interests (POIs) data [15]. Generally, the usage of big data and development of the 
parcel-based classification methods provide new possibilities for identifying the internal structure of urban land use and promoting efficient environmental risk management.

\section{Materials and Methods}

\subsection{Study Area}

The Beijing-Tianjin-Hebei urban agglomeration $\left(113^{\circ} 27^{\prime} 36^{\prime \prime}-119^{\circ} 50^{\prime} 53^{\prime \prime} \mathrm{E}, 36^{\circ} 2^{\prime} 8^{\prime \prime}-42^{\circ} 37^{\prime} 19^{\prime \prime} \mathrm{N}\right)$ is located in northern China, near the Bohai Sea (Figure 2). The study region consisted of Beijing, Tianjin municipality, and Hebei province, with a total area of 218,000 $\mathrm{km}^{2}$. The Beijing-Tianjin-Hebei urban agglomeration is the political, cultural, and economic center of China, which encompasses a population of approximately 112.5 million (8.1\% of China's total population) with a GDP of 8256.0 billion RMB (accounting for over 10.0\% of the national GDP). From 1978 to 2017, the proportion of population in Beijing-Tianjin-Hebei's urban areas increased from $17.9 \%$ to $56.1 \%$, with an average annual growth rate of $0.98 \%$ [37]. The rapid progress of urbanization and industrialization has resulted in substantial burgeons on energy production and the environment. The Beijing-Tianjin-Hebei region also experiences some of the most extreme water shortages and air and water pollution in the country $[38,39]$.

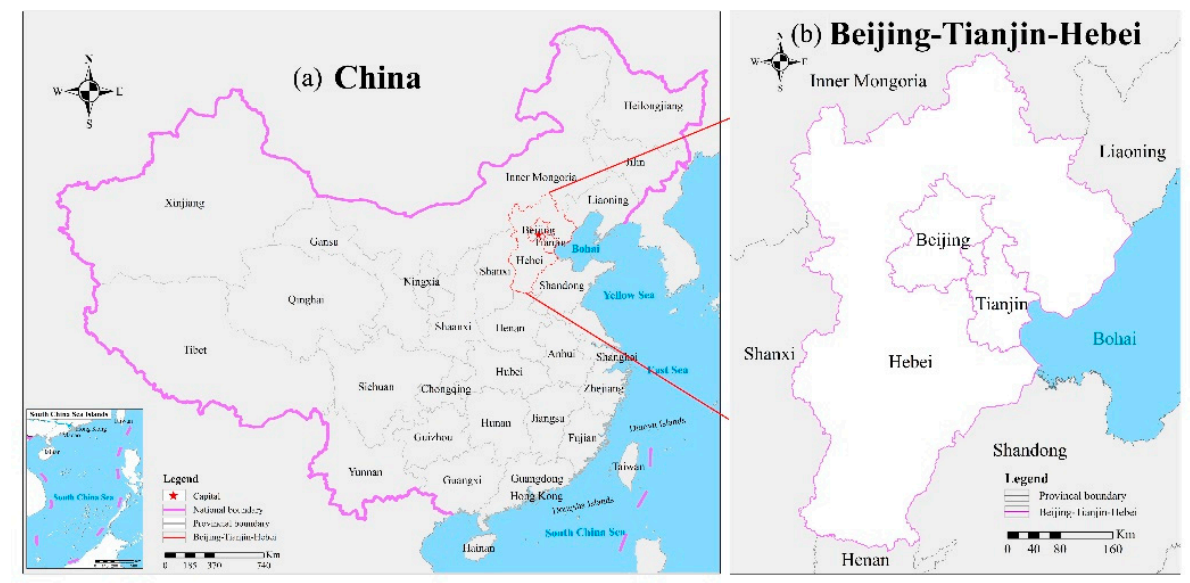

Figure 2. The location of the Beijing-Tianjin-Hebei urban agglomeration. (a) The location of the study area in China; (b) the Beijing-Tianjin-Hebei urban agglomeration.

\subsection{Main Components}

In this paper, we propose a method of fast identifying industrial land parcels using POIs and large-scale spatial data, including OpenStreetMap (abbreviated as OSM), population density, and land use data, etc. (Figure 3). The built-up land parcels are generated by the OSM and land use data. The POIs data are classified by industrial and residential types after cleaning, and then used to identify the possible industrial land parcels. We calculate the parcel population density (abbreviated as PPD) thresholds using environmental statistic data, which were officially released. Using the PPD, we can fast identify the industrial parcels from all the possibilities. The results can be validated by the random samples. Using the results, we discuss implications for environmental risk management in this area.

\subsection{Data Preparation and Analysis}

\subsubsection{POIs and Cleaning}

Points of interest (POIs) are often used to represent spatial location of companies, commercial points, traffic station, residential location, public services, parks, etc. [40]. POI data contain abundant information, including geographical position and the type of service provided at the point [41]. POIs have been widely used to identify the functional categories of built-up areas. 


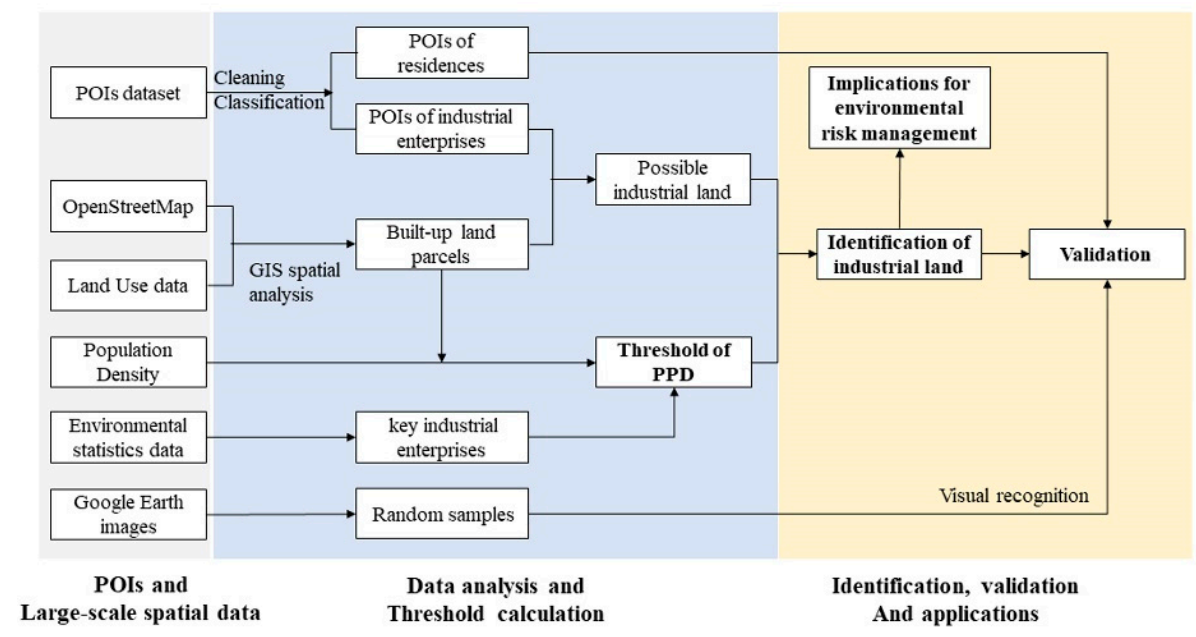

Figure 3. The framework for the method of quickly identifying industrial land parcels using Points of interest (POIs) and large-scale spatial data.

In this study, we use a POI dataset from our study area that was collected by AutoNavi, a Chinese mapping and location-based information services enterprise. The AuoNavi dataset consisted of $5,641,876$ POIs records. The POIs of polluting enterprises and residences were filtered according to type and name attributes. In addition, polluting enterprise POIs were classified into human settlement risks, soil pollution, and other possible pollutants. The descriptions of different types of POIs are shown in Table 1.

Table 1. The descriptions of different types of Points of interest (POIs).

\begin{tabular}{|c|c|c|}
\hline Types & Title 2 & Descriptions \\
\hline \multirow{3}{*}{$\begin{array}{l}\text { POIs of Polluting } \\
\text { enterprises }\end{array}$} & Human settlement risks & $\begin{array}{l}\text { The enterprises with potential environmental risks } \\
\text { (flammable or explosive) such as chemical, } \\
\text { firecracker, and petroleum enterprises, etc. }\end{array}$ \\
\hline & Soil pollution & $\begin{array}{l}\text { The enterprises with soil contamination risk which } \\
\text { mainly include ferrous metal mine mining and } \\
\text { processing industry, textile industry, paper industry, } \\
\text { metal manufacturing, etc. }\end{array}$ \\
\hline & Other pollutions & $\begin{array}{l}\text { The enterprises might cause other pollutants, such as } \\
\text { electricity generation, plastics industry, food } \\
\text { processing, clothing manufacturing, cement } \\
\text { manufacturing, etc. }\end{array}$ \\
\hline \multicolumn{2}{|c|}{ POIs of Residences } & The POIs that mainly represent residential parcels. \\
\hline
\end{tabular}

\subsubsection{OpenStreetMap and Processing}

OpenStreetMap (OSM) is an opening and free editable map of the world. The OpenStreetMap database is collected and updated by volunteers using tools such as handheld GPS units, digital cameras, and ground surveys.

The china-latest-free.shp.zip files were download from OSM, which contain various shape layers. Prior work has confirmed the completeness and geo-positioning information of the OSM dataset in China [42]. The OSM road layers consist of different road types ranging from motorways to gravel tracks as well as cycleways and footpaths. The railways layers include railways, trams, lifts, subways, etc. The river, stream, canal, drain feature classes are contained in the waterway layer. The Merge tool in ArcGIS was used to combine the line features from the OSM dataset (not including cycleways, footpaths, subways, and lifts) after clipped by the study area into a single, new output file, and the data were used to split developed land into independent parcels. 


\subsubsection{Land Use and Built-Up Land Parcel Analysis}

The land use vector dataset of the study area from 2015 was obtain from the Chinese Academy of Sciences Resource and Environment Science Data Center. This dataset was produced using human-computer interactive interpretation with Landsat TM data in a scale of 1:100,000 [43]. The data contains 6 classes and 25 subclasses of land use, including cropland, woodland, grassland, water body, built-up land, and undeveloped land [44]. The accuracy of the land use classifications is over $90 \%$, which meets the accuracy demands of land use and land cover study.

The built-upland in study area is $27,105.6 \mathrm{~km}^{2}$, accounting for $12.4 \%$ of the total area. The developed land data were split to independent parcels with the line features from the OSM dataset using the Cut Polygons tool in ArcGIS. This yielded 247,233 developed land parcels.

\subsubsection{Parcel Population Density Analysis}

Parcel population density (PPD) data were calculated based on the LandScan Global Population Database (2015). The database was developed by Oak Ridge National Laboratory (ORNL) using an innovative approach with GIS and remote sensing. The dataset is an estimate of population per 30 arc second pixel (which is at a higher resolution than 1 square kilometer) and updated annually [45]. LandScan data are regarded as an important data resource for global population distribution and accuracy and are regularly validated [46].

\subsubsection{Other Datasets}

We used environmental statistics data to calculate the threshold of population density for the industrial land parcels. Environmental statistics data are a relatively accurate dataset that contains basic information about most heavy polluting industries. Otherwise, we used Google Earth remote sensing data to test the accuracy of the industrial land identification. Google Earth (GE) is a planetary exploration tool with a high-resolution. The GIS functionality of GE has been extensively used in remote sensing validation as a form of "ground truthing" [47,48].

\subsection{Validation}

Here we use three indicators to validate the identification: accuracy $(\mathrm{A})$, precision $(\mathrm{P})$, and recall (R). We use visual recognition based on Google Earth remote sensing data to verify results. Here, the number of randomly selected land parcels is N, which contains industrial parcels (N1) and other land parcels (N0). For N1, TN1 is the number of correct results and FN1 is the number of incorrect results. Similarly, for N0, TN0 is the number of correct results and FN0 is the number of incorrect results. We use the results to calculate $\mathrm{A}, \mathrm{P}$, and $\mathrm{R}$ as below:

$$
\begin{gathered}
\mathrm{A}=(\mathrm{TN} 1+\mathrm{TN} 0) /(\mathrm{N} 1+\mathrm{N} 0), \\
\mathrm{P}=\mathrm{TN} 1 /(\mathrm{TN} 1+\mathrm{FN} 0), \\
\mathrm{R}=\mathrm{TN} 1 /(\mathrm{TN} 1+\mathrm{FN} 1) .
\end{gathered}
$$

\section{Results}

\subsection{The Industrial Enterprise POIs after Cleaning and Classifications}

There are 97,687 polluting enterprise POIs after filtering POI data (Table 2). The number of polluting POIs is eleven times that contained in the environmental statistics data. The polluting enterprise POIs were mainly distributed in Hebei province, accounting for $57.8 \%$ of the total in the study area. There are 84,644 polluting enterprise POIs falling inside developed land parcels. The proportion of polluting enterprise POIs in developed land parcels is $86.6 \%$ of the study area, and relatively high in Beijing and Tianjin. 
Table 2. The numbers of the industrial enterprise POIs in the built-up land parcels.

\begin{tabular}{cccc}
\hline Provinces & $\begin{array}{c}\text { Numbers of Polluting } \\
\text { Enterprise POIs }\end{array}$ & $\begin{array}{c}\text { Numbers of Polluting Enterprise } \\
\text { POIs in Built-Up Land Parcel }\end{array}$ & Percent/\% \\
\hline Beijing & 22,288 & 20,394 & 91.5 \\
Tianjin & 18,903 & 17,235 & 91.2 \\
Hebei & 56,496 & 47,015 & 83.2 \\
Total & 97,687 & 84,644 & 86.6 \\
\hline
\end{tabular}

\subsection{Identifying the Possible Industrial Land Parcels}

We identified 8939 enterprises from the environmental statistics data in the study area, Hebei and Tianjin, accounting for over $90 \%$ of the total in the dataset (Table 3). Due to the accuracy of land use data, 6304 enterprises (about $70.5 \%$ of environmental statistics data) fall inside developed land parcels after the spatial analysis. The proportion of the selected enterprises in developed parcels is $59.7 \%$ in Hebei, which is far less than in Beijing and Tianjin. This is in large part due to some industry categories, such as mineral enterprises and brick factories, being located further from downtown and have a relatively small building volume. There are 742 mineral enterprises and brick factories which are not in parcels, about $12.2 \%$ of the total environmental statistics data from Hebei.

Table 3. The numbers of enterprises from environmental statistics in the built-up land parcels.

\begin{tabular}{cccc}
\hline Provinces & $\begin{array}{c}\text { Numbers of Environmental } \\
\text { Statistics Data }\end{array}$ & $\begin{array}{c}\text { Numbers of Environmental } \\
\text { Statistics Data in Developed Parcels }\end{array}$ & Percent/\% \\
\hline Beijing & 843 & 786 & 93.2 \\
Tianjin & 2015 & 1887 & 93.6 \\
Hebei & 6081 & 3632 & 59.7 \\
Total & 8939 & 6305 & 70.5 \\
\hline
\end{tabular}

\subsection{The PPD Threshold of the Industrial Land Parcels}

The PPD of the built land parcels was between 0-78,693 people/ $\mathrm{km}^{2}$. We found significant negative correlation between the spatial distribution of industrial land parcels and their population density. To select the threshold of the PPD for industrial parcels, we analyzed the PPD changes and the cumulative percentage of enterprises (Figure 4). Finally, we estimated that $4500 \mathrm{per} / \mathrm{km}^{2}$ is the PPD threshold of industrial land parcels in this study, when the cumulative percentage is over $80 \%$. If the PPD value of built-up land parcels is less than $4500 \mathrm{per} / \mathrm{km}^{2}$, we regard the parcels as industrial land.

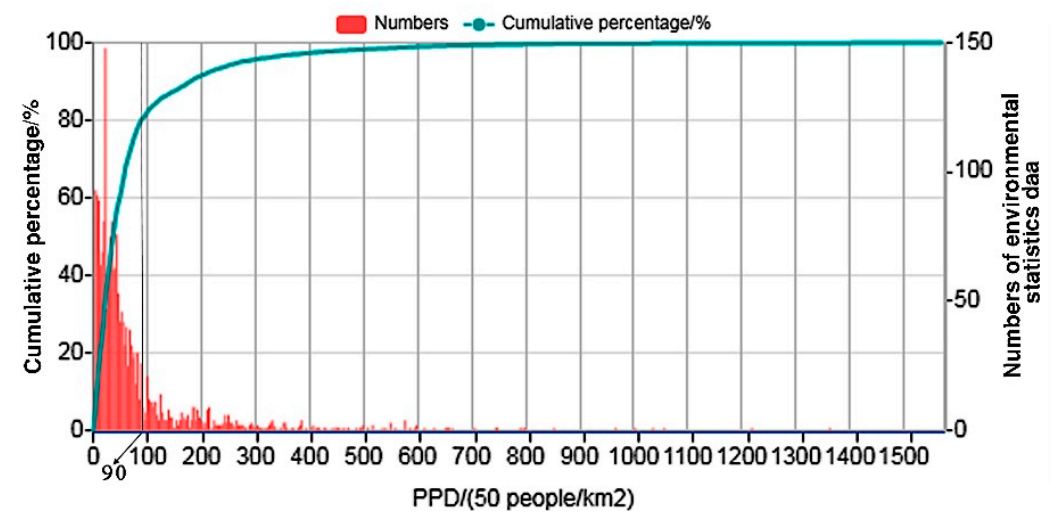

Figure 4. The cumulative percentage of the built land parcels using the environmental statistics data for the parcel population density (PPD). 


\subsection{Identifying the Industrial Land Parcels Using POIs}

The total number of identified industrial parcels is 17,937 , accounting for $7.3 \%$ of industrial land parcels. The number of industrial parcels in Beijing, Tianjin, and Hebei are 2831, 2712, and 12,394, respectively. The area of industrial land identified using polluting enterprise POIs data in the study area is $8325 \mathrm{~km}^{2}$ (Figure 5a), accounting for $30.7 \%$ of the developed area. The industrial parcels of Beijing are mainly distributed outside the fifth ring road (Figure $5 b$ ), with an area of $1034 \mathrm{~km}^{2}$. The industrial area of Tianjin is $1336 \mathrm{~km}^{2}$, mainly distributed outside of the ring road and Binhai New District (Figure 5c). The industrial area of Hebei Province is $5955 \mathrm{~km}^{2}$, higher than in Beijing and Tianjin, accounting for $71.5 \%$ of the total industrial area, and widely distributed in the southeastern Hebei Province.
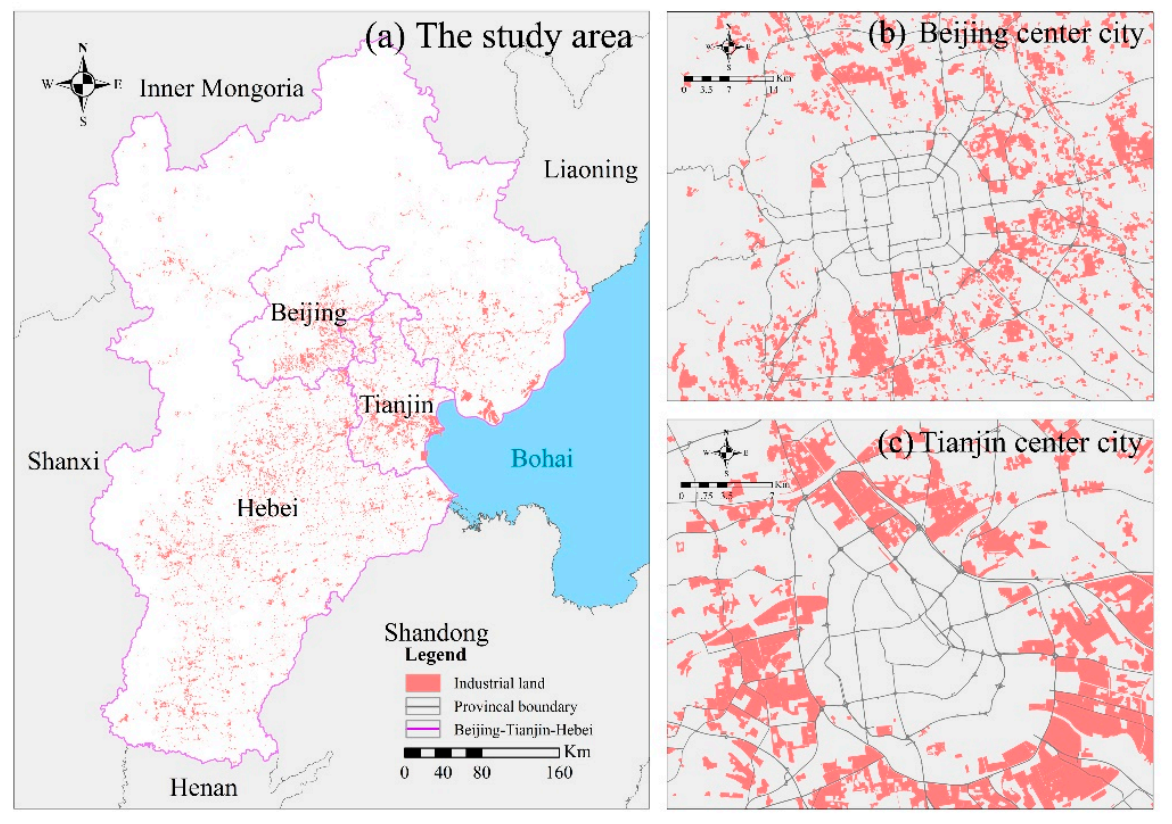

Figure 5. The spatial distribution of the identified industrial land parcels using POIs. (a) The study area; (b) Beijing City; (c) Tianjin City.

\subsection{Validating Results}

We randomly selected 2000 land parcels from different cities, accounting for over $0.8 \%$ of the total land parcels in the study area. These randomly selected parcels contained 265 industrial parcels and 1735 non-industrial parcels according to our analysis and we verified these results using visual recognition in the Google Earth engine. Results show that the indicators of the accuracy (A), precision $(\mathrm{P})$, recall $(\mathrm{R})$ are $87.1 \%, 66.4 \%, 68.1 \%$, respectively. The values for $\mathrm{A}$ are high, suggesting our method can identify industrial parcels relatively well. For the huge number of land parcels and the uncertainty of the method, the indicator of precision $(\mathrm{P})$ and recall $(\mathrm{R})$ is relatively low. Overall, the results can reflect the status of the industrial land parcels, which might satisfy the research of the distribution characteristics and impacts of the industrial land.

\section{Discussion}

\subsection{Distinguishing the Land Parcels with Human Settlement Risks}

Urbanization in recent years has transformed landscapes into mixed industrial and residential zones, which might led to a severe human settlement risk [49]. Using the identified industrial parcels, we distinguished the risk industrial land parcels with distance to the closest residence POIs less than 2 $\mathrm{km}$. There are over $350 \mathrm{~km}^{2}$ of risk industrial parcels mainly distributed in Tianjin Municipality and Tangshan city, accounting for $68.0 \%$ of the total risk industrial parcels area. As shown in Figure 6, 
the high-risk industrial parcels are mainly distributed in Binhai New District and Dongli District in the Tianjin Municipality. In Tangshan city, the high-risk industrial parcels are mainly distributed in Luannan and Laoting counties. Tianjin and Tangshan are both important heavy industry cities in northern China, with many polluting factories and storage parcels in the urban areas. The distribution of the industrial parcels nearby residential areas might have potential impacts on citizens' health and safety. The government should pay greater attention to pollution risk management and control in order to guarantee the safety of citizens in the above areas. We suggest to optimize the structure of urban land use, and transfer the polluted industrial land inside the city. For the industrial parks, a certain safe distance from urban residential areas should be maintained.
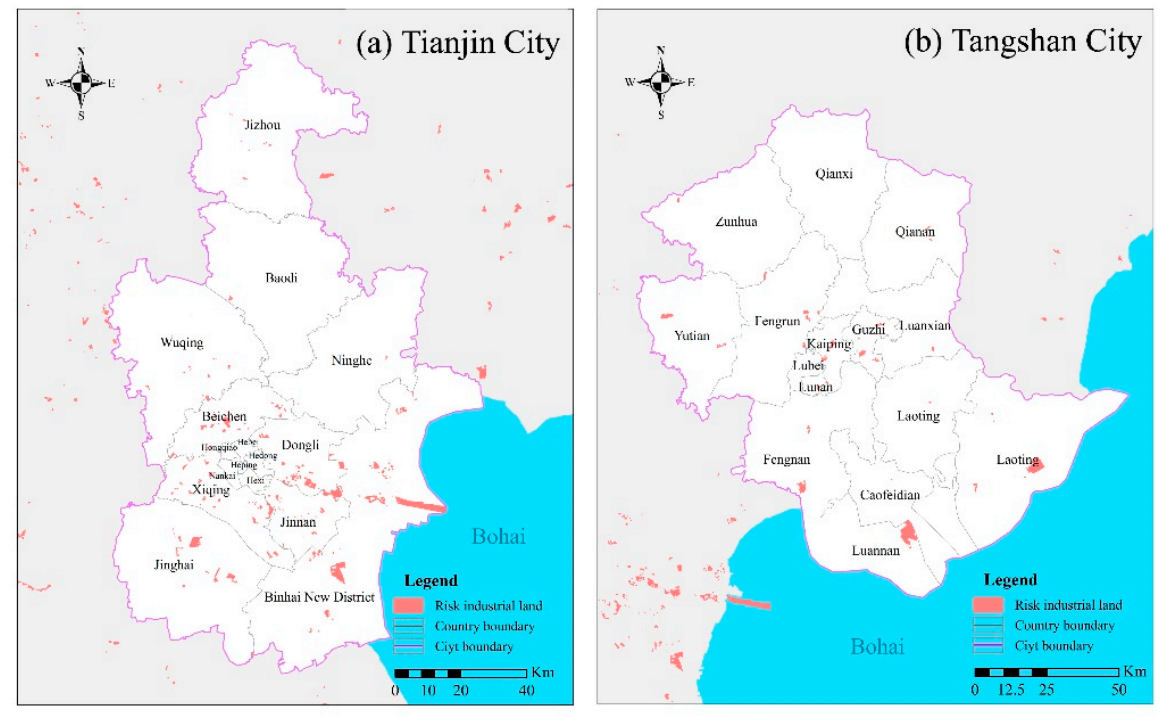

Figure 6. The distribution of the industrial land parcels with high human settlement risks in Tianjin and Tangshan City. (a) Tianjin City; (b) Tangshan City.

\subsection{Screening Soil Contamination Risk in Industrial Parcels}

Contaminated industrial land parcels are the significant risks in the urban area, but they also can be redeveloped as urban construction land after remediation [50,51]. According to the attributes of industrial enterprise POIs, 9587 potential POIs were screened out with the contaminated risks. After spatial analysis of the potential POIs and industrial land parcels, the soil contaminated industrial land parcels were differentiated. There are nearly $2400 \mathrm{~km}^{2}$ of soil contaminated industrial parcels in the study area, accounting for $28.8 \%$ of the total identified industrial land parcels. Beijing, Tianjin, and Hebei have 200,425 and $1765 \mathrm{~km}^{2}$ respectively. The contaminated parcels are mainly distributed in southeastern Beijing, southern Tianjin, and main cities of Hebei (Figure 7). Beijing is promoting the policy of decentralization of the non-capital functions, and the industrial enterprises relocation is one of the essential tasks [33]. The identified contaminated industrial parcels will be an important issue for the urban planning and regeneration. We suggest soil contamination monitoring and remediation before the reuse of the industrial parcels, and making reasonable reuse functions according to the pollution characteristics. For other cities (e.g., Tianjin, Tangshan), the government should carry out strict monitoring and control programs for the existing industrial parcels with higher pollution risk to ensure that the surrounding residents are not affected.

\subsection{Uncertainty and Disadvantages}

We can identify industrial parcels using POIs and high-resolution spatial data, but the accuracy of our approach might be influenced by many factors, such as data completeness and PPD threshold selection. The OSM data used in this study currently does not contain all the line features in the study area $[52,53]$. Due to low-resolution Landsat remote sensing images, some developed land parcels 
cannot be accurately identified [54,55]. Furthermore, the accuracy of industrial land identification is influenced by the selection of PPD thresholds because of differences in population densities in different regions. Missing OSM data, selection of PPD thresholds, and mixed land use might cause declines in identification accuracy, especially in urban-rural interfaces or small towns. Our current results can be used to guide urban planning and environmental protection but future research should aim to improve and optimize this approach.
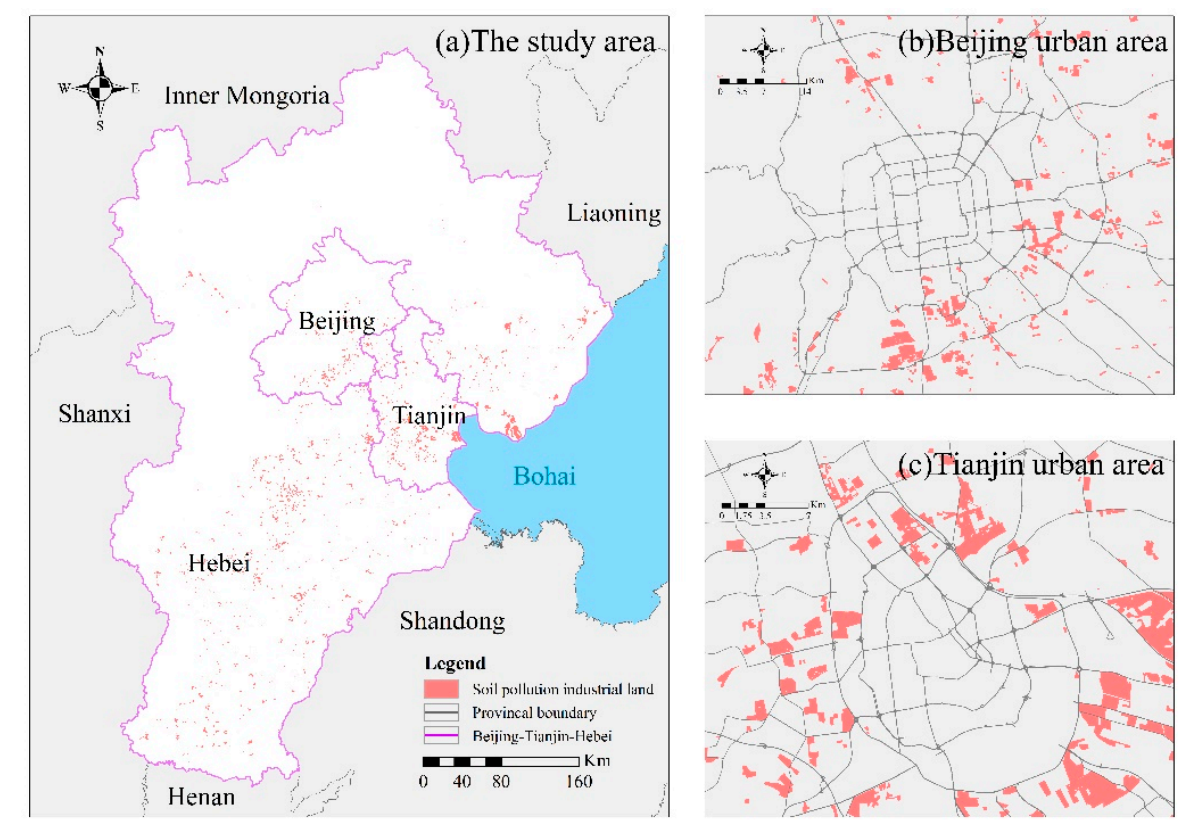

Figure 7. The industrial land parcels where soil contamination risk suggests key monitoring and remediation. (a) The study area; (b) Beijing urban area; (c) Tianjin urban area.

\section{Conclusions}

\subsection{Main Conclusions}

In order to better understand the internal composite structure of urban land use and its effect on the human settlement environment, we propose a method of quickly identifying industrial land parcels using POIs and large-scale spatial data, and discuss the implications of the results for environmental risk management. We find that our method can easily detect more industrial parcels using POIs than might using environmental statistics data. The accuracy and precision of the industrial parcel identifications is satisfactory for future research on the internal structure of urban land use and the impact of urban industry on residential areas. Using this method, we identify the total industrial land parcels with an area of $8325 \mathrm{~km}^{2}$ in the Beijing-Tianjin-Hebei urban agglomeration, accounting for $30.7 \%$ of the area of built-up land, mainly distributed outside the fifth ring road of Beijing, Binhai new district of Tianjin, and main cities of Hebei. According to the result, we can find that there are over $350 \mathrm{~km}^{2}$ of industrial land parcels with high human settlement risks in Tianjin and Tangshan. Thus, the optimization of the land use structure, strict monitoring, and reasonable transformation of industrial parcels should be promoted in the area. Furthermore, over $28.8 \%$ of the industrial land parcels might be soil contaminated, mainly distributed in southeastern Beijing, Tianjin, and Tangshan. We suggest soil contamination monitoring and remediation before the reuse of industrial parcels in Beijing, and stricter monitoring and control programs for the existing industrial parcels in other cities (e.g., Tianjin, Tangshan). The results and implications might be used for urban planning, regional environmental pollution prevention, and human settlement risk control. 


\subsection{Policy Implications}

(1) The industrial land parcels are widely distributed in urban areas, with the characteristic of mixed structure with residential parcels. Identifying industrial parcels is essential for urban planners and land use researchers to study the internal structure of urban land use and its effects on human settlement environment. Using the POIs and large-scale spatial data (e.g., OSM, land use and population density dataset), we suggest that policy makers pay more attention to industrial parcels and their risks. Optimization of urban land use structure, regeneration of relocated industrial parcels, and monitoring for high-risk parcels should be important tasks for the government.

(2) In urban agglomeration and megacities (e.g., Beijing), the industrial parcels normally have disordered distribution and greater environmental risks for nearby residents. Therefore, the government should promote the relocation of the pollution intensified industrial parcels and implement much stricter supervision and monitoring, potentially for all industrial parcels. Meanwhile, the reuse of the industrial parcels must be evaluated firstly, considering their contamination characteristics and all the potential effects on human health. Reasonable restructuring and regeneration for urban land use can reduce environmental risks in the urban areas with mixed industrial and residential parcels.

(3) It is crucial for some heavy industry oriented cities (e.g., Tianjin, Tangshan) to develop more integrated management towards efficient environmental risk control, for their concentrated and numerous industrial parcels in urban areas. For industrial parks or concentrated industrial parcels, a security distance from urban residential areas should be defined and well maintained. We suggest planning more green space surrounding industrial parks and heavy polluting industries (e.g., steel factory, petrochemical park).

Author Contributions: Z.W.: Investigation, Methodology, Writing and editing; J.Z.: Software, Resources and Formal analysis; S.L.: Validation, Visualization; Y.L.: Conceptualization, Methodology, Reviewing and Supervision. All authors have read and agreed to the published version of the manuscript.

Funding: This research was supported by National Natural Science Foundation of China (71774096) and the Strategic Environmental Assessment of Beijing-Tianjin-Hebei Region Project of the Ministry of Environmental Protection (20161660220).

Acknowledgments: We would like to thank Max Lambert at the Yale University for his assistance with English language and grammatical editing of the manuscript.

Conflicts of Interest: The authors declare no conflict of interest.

\section{References}

1. Wang, Q.; Tapia Granados, J.A. Economic growth and mental health in 21st century China. Soc. Sci. Med. 2019, 220, 387-395. [CrossRef] [PubMed]

2. Song, M.; Peng, J.; Wang, J.; Zhao, J. Environmental efficiency and economic growth of China: A Ray slack-based model analysis. Eur. J. Oper. Res. 2018, 269, 51-63. [CrossRef]

3. Cui, X.; Fang, C.; Liu, H.; Liu, X. Assessing sustainability of urbanization by a coordinated development index for an Urbanization-Resources-Environment complex system: A case study of Jing-Jin-Ji region, China. Ecol. Indic. 2019, 96, 383-391. [CrossRef]

4. Ye, C.; Chen, M.; Duan, J.; Yang, D. Uneven development, urbanization and production of space in the middle-scale region based on the case of Jiangsu province, China. Habitat Int. 2017, 66, 106-116. [CrossRef]

5. Wang, J.; Lin, Y.; Glendinning, A.; Xu, Y. Land-use changes and land policies evolution in China's urbanization processes. Land Use Policy 2018, 75, 375-387. [CrossRef]

6. Zhao, H.; Guo, S.; Zhao, H. Characterizing the Influences of Economic Development, Energy Consumption, Urbanization, Industrialization, and Vehicles Amount on PM2.5 Concentrations of China. Sustainability 2018, 10, 2574. [CrossRef]

7. Wang, S.; Zhou, C.; Li, G.; Feng, $\mathrm{K} . \mathrm{CO}_{2}$, economic growth, and energy consumption in China's provinces: Investigating the spatiotemporal and econometric characteristics of China's $\mathrm{CO}_{2}$ emissions. Ecol. Indic. 2016, 69, 184-195. [CrossRef] 
8. Fu, G.; Wang, J.; Yan, M. Anatomy of Tianjin Port fire and explosion: Process and causes. Process Saf. Prog. 2016, 35, 216-220. [CrossRef]

9. Chen, M.; Liu, W.; Lu, D. Challenges and the way forward in China's new-type urbanization. Land Use Policy 2016, 55, 334-339. [CrossRef]

10. Ma, L.; Li, M.; Ma, X.; Cheng, L.; Du, P.; Liu, Y. A review of supervised object-based land-cover image classification. ISPRS J. Photogramm. Remote Sens. 2017, 130, 277-293. [CrossRef]

11. Sawant, S.S.; Prabukumar, M. A review on graph-based semi-supervised learning methods for hyperspectral image classification. Egypt. J. Remote Sens. Space Sci. 2018. [CrossRef]

12. Ali, M.Z.; Qazi, W.; Aslam, N. A comparative study of ALOS-2 PALSAR and landsat-8 imagery for land cover classification using maximum likelihood classifier. Egypt. J. Remote Sens. Space Sci. 2018, 21, S29-S35. [CrossRef]

13. Sinha, S.; Sharma, L.K.; Nathawat, M.S. Improved Land-use/Land-cover classification of semi-arid deciduous forest landscape using thermal remote sensing. Egypt. J. Remote Sens. Space Sci. 2015, 18, 217-233. [CrossRef]

14. Long, Y.; Zhai, W.; Shen, Y.; Ye, X. Understanding uneven urban expansion with natural cities using open data. Landsc. Urban Plan. 2018, 177, 281-293. [CrossRef]

15. Liu, X.; Long, Y. Automated identification and characterization of parcels with OpenStreetMap and points of interest. Environ. Plan. B Plan. Des. 2015, 43, 341-360. [CrossRef]

16. Lang, W.; Long, Y.; Chen, T. Rediscovering Chinese cities through the lens of land-use patterns. Land Use Policy 2018, 79, 362-374. [CrossRef]

17. Jiang, G.; Ma, W.; Wang, D.; Zhou, D.; Zhang, R.; Zhou, T. Identifying the internal structure evolution of urban built-up land sprawl (UBLS) from a composite structure perspective: A case study of the Beijing metropolitan area, China. Land Use Policy 2017, 62, 258-267.

18. Zhang, W.; Li, W.; Zhang, C.; Hanink, D.M.; Liu, Y.; Zhai, R. Analyzing horizontal and vertical urban expansions in three East Asian megacities with the SS-coMCRF model. Landsc. Urban Plan. 2018, 177, $114-127$. [CrossRef]

19. Yang, Y.; Liu, Y.; Li, Y.; Du, G. Quantifying spatio-temporal patterns of urban expansion in Beijing during 1985-2013 with rural-urban development transformation. Land Use Policy 2018, 74, 220-230. [CrossRef]

20. Zhang, Z.; Li, N.; Wang, X.; Liu, F.; Yang, L. A Comparative Study of Urban Expansion in Beijing, Tianjin and Tangshan from the 1970s to 2013. Remote Sens. 2016, 8, 496. [CrossRef]

21. Bi, C.; Chen, Y.; Zhao, Z.; Li, Q.; Zhou, Q.; Ye, Z.; Ge, X. Characteristics, sources and health risks of toxic species (PCDD/Fs, PAHs and heavy metals) in PM2.5 during fall and winter in an industrial area. Chemosphere 2020, 238, 124620. [CrossRef] [PubMed]

22. Zhang, Z.Y.; Shao, C.F.; Guan, Y.; Xue, C.Y. Socioeconomic factors and regional differences of PM2.5 health risks in China. J. Environ. Manag. 2019, 251, 10. [CrossRef] [PubMed]

23. Zhang, W.; Li, W.; Zhang, C.; Hanink, D.M.; Li, X.; Wang, W. Parcel-based urban land use classification in megacity using airborne LiDAR, high resolution orthoimagery, and Google Street View. Comput. Environ. Urban Syst. 2017, 64, 215-228. [CrossRef]

24. Wang, T.; Kazak, J.; Han, Q.; de Vries, B. A framework for path-dependent industrial land transition analysis using vector data. Eur. Plan. Stud. 2019, 27, 1391-1412. [CrossRef]

25. Jiang, G.; Ma, W.; Qu, Y.; Zhang, R.; Zhou, D. How does sprawl differ across urban built-up land types in China? A spatial-temporal analysis of the Beijing metropolitan area using granted land parcel data. Cities 2016, 58, 1-9. [CrossRef]

26. Sun, C.; Sun, C.; Yang, Z.; Zhang, J.; Deng, Y. Urban Land Development for Industrial and Commercial Use: A Case Study of Beijing. Sustainability 2016, 8, 1323. [CrossRef]

27. Guan, Y.; Shao, C.; Gu, Q.; Ju, M.; Zhang, Q. Method for Assessing the Integrated Risk of Soil Pollution in Industrial and Mining Gathering Areas. Int. J. Environ. Res. Public Health 2015, 12, 14589-14609. [CrossRef]

28. Liang, S.Y.; Cui, J.L.; Bi, X.Y.; Luo, X.S.; Li, X.D. Deciphering source contributions of trace metal contamination in urban soil, road dust, and foliar dust of Guangzhou, southern China. Sci. Total Environ. 2019, 695, 12. [CrossRef]

29. Sun, Y.M.; Li, H.; Guo, G.L.; Semple, K.T.; Jones, K.C. Soil contamination in China: Current priorities, defining background levels and standards for heavy metals. J. Environ. Manag. 2019, 251, 7. [CrossRef] 
30. Huang, Y.Y.; Zhou, B.H.; Li, N.; Li, Y.M.; Han, R.R.; Qi, J.C.; Lu, X.H.; Li, S.; Feng, C.Y.; Liang, S. Spatial-temporal analysis of selected industrial aquatic heavy metal pollution in China. J. Clean. Prod. 2019, 238, 10. [CrossRef]

31. Chen, L.; Wang, Y.M.; Li, P.W.; Ji, Y.Q.; Kong, S.F.; Li, Z.Y.; Bai, Z.P. A land use regression model incorporating data on industrial point source pollution. J. Environ. Sci. 2012, 24, 1251-1258. [CrossRef]

32. Zhang, Q.; Zheng, Y.; Tong, D.; Shao, M.; Wang, S.; Zhang, Y.; Xu, X.; Wang, J.; He, H.; Liu, W.; et al. Drivers of improved PM2.5 air quality in China from 2013 to 2017. Proc. Natl. Acad. Sci. USA 2019, 116, 24463-24469. [CrossRef]

33. Li, T.; Liu, Y.; Wang, C.; Olsson, G.; Wang, Z.; Wang, H. Decentralization of the non-capital functions of Beijing: Industrial relocation and its environmental effects. J. Clean. Prod. 2019, 224, 545-556. [CrossRef]

34. Huang, H.B.; Chen, Y.L.; Clinton, N.; Wang, J.; Wang, X.Y.; Liu, C.X.; Gong, P.; Yang, J.; Bai, Y.Q.; Zheng, Y.M.; et al. Mapping major land cover dynamics in Beijing using all Landsat images in Google Earth Engine. Remote Sens. Environ. 2017, 202, 166-176. [CrossRef]

35. Chen, C.R.; Du, Z.B.; Zhu, D.H.; Zhang, C.; Yang, J.Y. Land Use Classification in Construction Areas Based on Volunteered Geographic Information. In Proceedings of the IEEE 2016 Fifth International Conference on Agro-Geoinformatics, Tianjin, China, 18-20 July 2016; pp. 32-35.

36. Jia, Y.; Ge, Y.; Ling, F.; Guo, X.; Wang, J.; Wang, L.; Chen, Y.; Li, X. Urban Land Use Mapping by Combining Remote Sensing Imagery and Mobile Phone Positioning Data. Remote Sens. 2018, 10, 446. [CrossRef]

37. Wei, W.; Wang, X.; Zhu, H.; Li, J.; Zhou, S.; Zou, Z.; Li, J.S. Carbon emissions of urban power grid in Jing-Jin-Ji region: Characteristics and influential factors. J. Clean. Prod. 2017, 168, 428-440. [CrossRef]

38. Wang, Y.; Liu, H.; Mao, G.; Zuo, J.; Ma, J. Inter-regional and sectoral linkage analysis of air pollution in Beijing-Tianjin-Hebei (Jing-Jin-Ji) urban agglomeration of China. J. Clean. Prod. 2017, 165, 1436-1444. [CrossRef]

39. Zhao, D.; Tang, Y.; Liu, J.; Tillotson, M.R. Water footprint of Jing-Jin-Ji urban agglomeration in China. J. Clean. Prod. 2017, 167, 919-928. [CrossRef]

40. Zhang, X.; Du, S.; Wang, Q. Hierarchical semantic cognition for urban functional zones with VHR satellite images and POI data. ISPRS J. Photogramm. Remote Sens. 2017, 132, 170-184. [CrossRef]

41. Dong, R.; Li, S.; Zhang, Y.; Zhang, N.; Wang, T.; Tan, X.; Fu, X. Analysis of urban environmental problems based on big data from the urban municipal supervision and management information system. Ecol. Indic. 2018, 94, 52-69. [CrossRef]

42. Zheng, S.; Zheng, J. Assessing the Completeness and Positional Accuracy of OpenStreetMap in China. In Thematic Cartography for the Society; Bandrova, T., Konecny, M., Zlatanova, S., Eds.; Springer International Publishing: Cham, Switzerland, 2014; pp. 171-189.

43. Liu, J.; Kuang, W.; Zhang, Z.; Xu, X.; Qin, Y.; Ning, J.; Zhou, W.; Zhang, S.; Li, R.; Yan, C.; et al. Spatiotemporal characteristics, patterns, and causes of land-use changes in China since the late 1980s. J. Geogr. Sci. 2014, 24, 195-210. [CrossRef]

44. Ning, J.; Liu, J.; Kuang, W.; Xu, X.; Zhang, S.; Yan, C.; Li, R.; Wu, S.; Hu, Y.; Du, G.; et al. Spatiotemporal patterns and characteristics of land-use change in China during 2010-2015. J. Geogr. Sci. 2018, 28, 547-562. [CrossRef]

45. Azar, D.; Engstrom, R.; Graesser, J.; Comenetz, J. Generation of fine-scale population layers using multi-resolution satellite imagery and geospatial data. Remote Sens. Environ. 2013, 130, 219-232. [CrossRef]

46. Leyk, S.; Gaughan, A.E.; Adamo, S.B.; de Sherbinin, A.; Balk, D.; Freire, S.; Rose, A.; Stevens, F.R.; Blankespoor, B.; Frye, C.; et al. The spatial allocation of population: A review of large-scale gridded population data products and their fitness for use. Earth Syst. Sci. Data 2019, 11, 1385-1409. [CrossRef]

47. Zhao, Y.; Gong, P.; Yu, L.; Hu, L.; Li, X.; Li, C.; Zhang, H.; Zheng, Y.; Wang, J.; Zhao, Y.; et al. Towards a common validation sample set for global land-cover mapping. Int. J. Remote Sens. 2014, 35, 4795-4814. [CrossRef]

48. Madugundu, R. Detection of Land Use and Land Cover Changes in Dirab Region of Saudi Arabia Using Remotely Sensed Imageries. Am. J. Environ. Sci. 2014, 10, 8-18. [CrossRef]

49. Meng, Y.; Yan, X.; Zhao, D.; Mannan, M.S. Challenges and reflections on the development of urban refineries in China. J. Loss Prev. Process Ind. 2018, 56, 1-9. [CrossRef]

50. Liu, L.; Li, W.; Song, W.; Guo, M. Remediation techniques for heavy metal-contaminated soils: Principles and applicability. Sci. Total Environ. 2018, 633, 206-219. [CrossRef] 
51. Wu, Q.; Zhang, X.; Liu, C.; Chen, Z. The de-industrialization, re-suburbanization and health risks of brownfield land reuse: Case study of a toxic soil event in Changzhou, China. Land Use Policy 2018, 74, 187-194. [CrossRef]

52. Bright, J.; De Sabbata, S.; Lee, S.; Ganesh, B.; Humphreys, D.K. OpenStreetMap data for alcohol research: Reliability assessment and quality indicators. Health Place 2018, 50, 130-136. [CrossRef]

53. Zhang, Y.; Li, X.; Wang, A.; Bao, T.; Tian, S. Density and diversity of OpenStreetMap road networks in China. J. Urban Manag. 2015, 4, 135-146. [CrossRef]

54. Peng, W.; Wang, G.; Zhou, J.; Zhao, J.; Yang, C. Studies on the temporal and spatial variations of urban expansion in Chengdu, western China, from 1978 to 2010. Sustain. Cities Soc. 2015, 17, 141-150. [CrossRef]

55. Zhang, Z.; Wang, X.; Zhao, X.; Liu, B.; Yi, L.; Zuo, L.; Wen, Q.; Liu, F.; Xu, J.; Hu, S. A 2010 update of National Land Use/Cover Database of China at 1:100,000 scale using medium spatial resolution satellite images. Remote Sens. Environ. 2014, 149, 142-154. [CrossRef]

(C) 2019 by the authors. Licensee MDPI, Basel, Switzerland. This article is an open access article distributed under the terms and conditions of the Creative Commons Attribution (CC BY) license (http://creativecommons.org/licenses/by/4.0/). 